\title{
New Antibiotics
}

It appears that new antibiotics are not developed with the objective of being significantly better than agents already on the market and that offer only slight improvements over existing antibiotics. In the 1980s there was a glut of cephalosporins, with the significant advance that some offered activity against anaerobic bacteria, while others were being offered because of their activity against Pseudomonas. The 1990s brought the development of various quinolones. The initial entrant into this area was ciprofloxacin. Since its emergence, several other quinolones have appeared.

It is interesting to note that, although the newer quinolones have activity against anaerobic bacteria, the pharmaceutical industry does not view their products as major agents to be used in the treatment of gynecologic infections. The pathway leading to their use in gynecology (quinolones are contraindicated in pregnancy) has been the treatment of chlamydial and gonococcal cervicitis, with emphasis on the treatment of pelvic inflammatory disease. The newer agents have not proven to be of benefit over existing agents, except for differences in dosage regimens. In most cases for oral therapy, the dosage change is from twice a day to once a day, the advantage being the possibility of better compliance. There may be other theoretical benefits, but often there is no significant data to support these proposed benefits.

Perhaps when new antibiotics are being developed the pharmaceutical industry should determine, with the assistance of obstetric/gynecologic infectious disease physicians, the objectives they would like to attain.

In the recent past, the role of antibiotics in obstetrics/gynecology has not received credible attention. This has resulted in no significant improvement in antimicrobial advancement for the treatment of obstetric/gynecologic infections. Too much effort is going into areas that are not significant with regard to reducing infectious morbidity in the obstetric/gynecologic patients.

Sebastian Faro, MD, PhD

Editor-in-Chief 


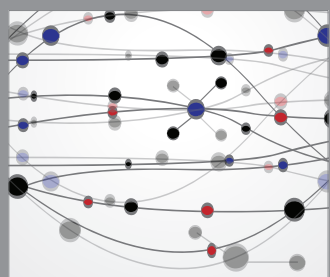

The Scientific World Journal
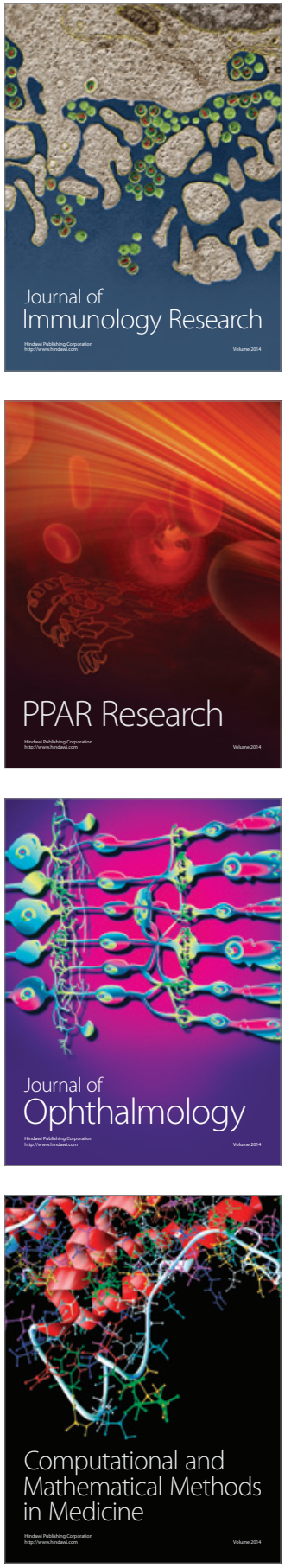

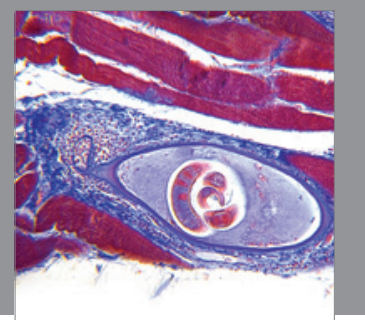

Gastroenterology

Research and Practice
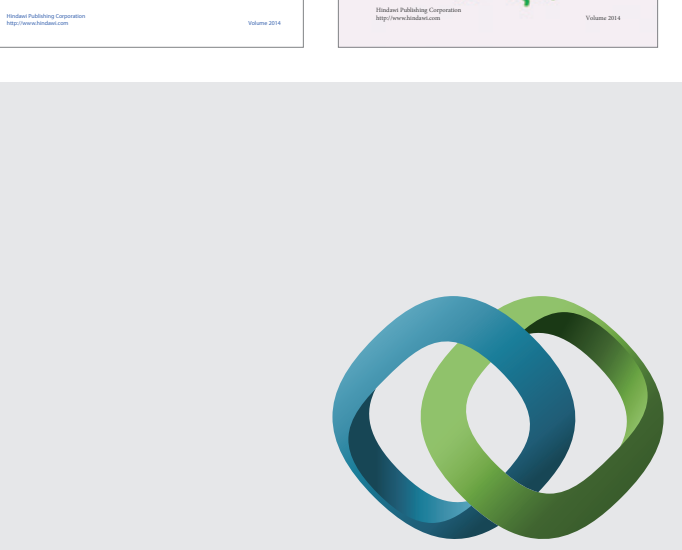

\section{Hindawi}

Submit your manuscripts at

http://www.hindawi.com
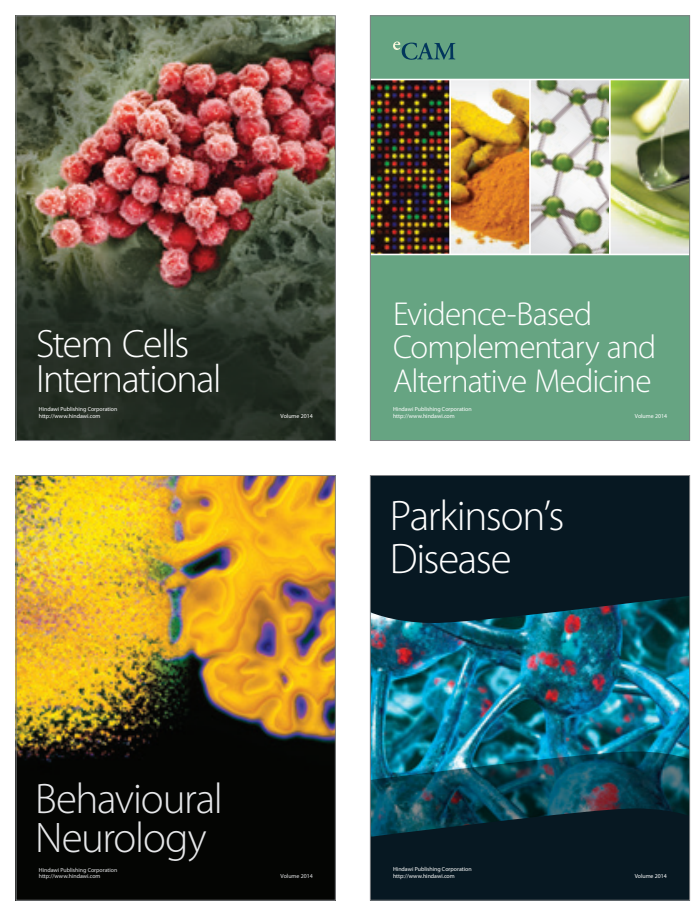

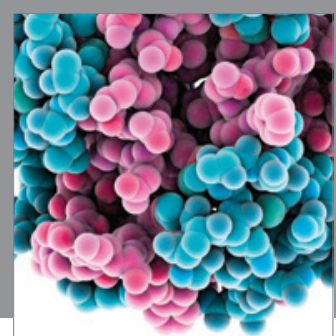

Journal of
Diabetes Research

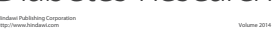

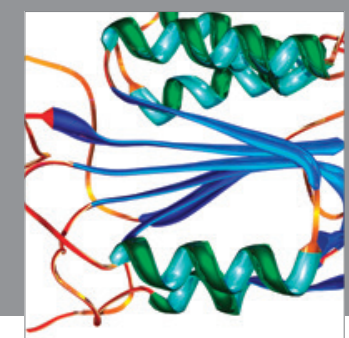

Disease Markers
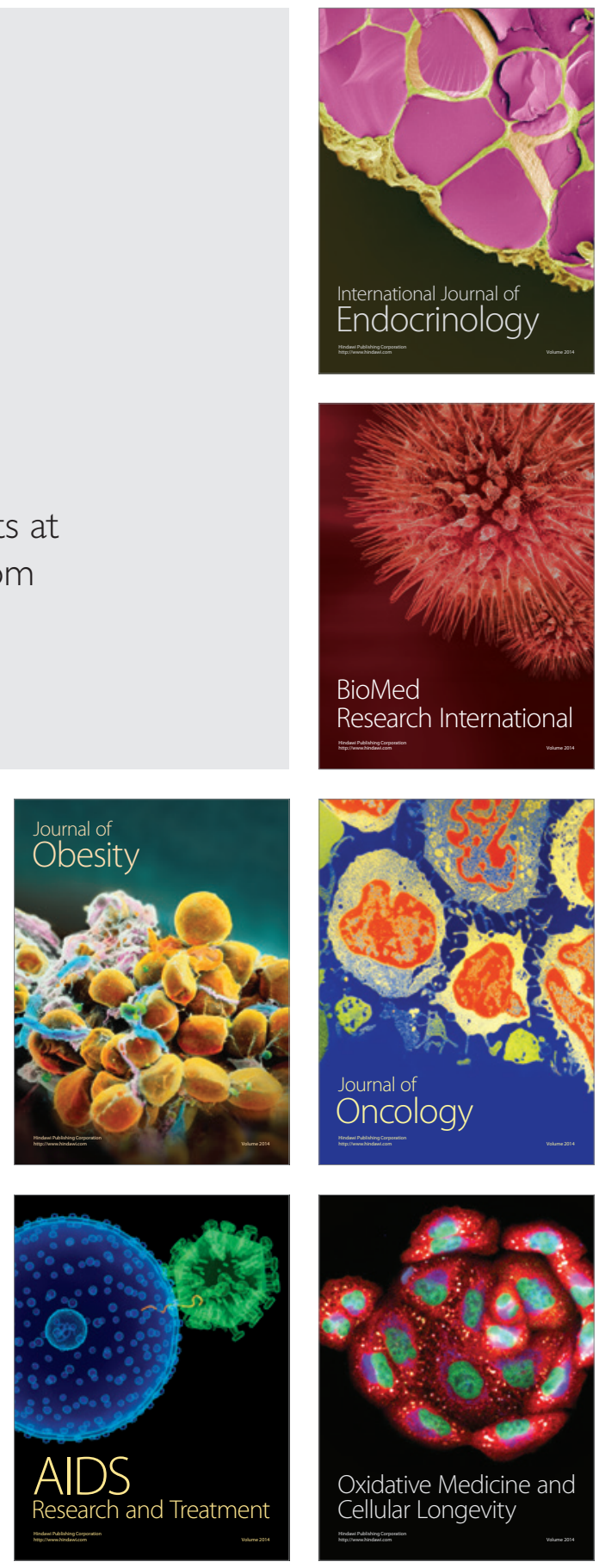